\title{
A CONTRIBUIÇÃO NARRATIVA DOS ELEMENTOS VISUAIS NA FORMAÇÃO DE ESPAÇOS FÍLMICOS EM SEGUINDO EM FRENTE (ARUITEMO ARUITEMO) ${ }^{1}$ THE VISUAL ELEMENTS NARRATIVE CONTRIBUTION TO THE FORMATION OF FILMIC SPACES IN "STILL WALKING" (ARUITEMO ARUITEMO)
}

Mari Sugai

Resumo: Na intersecção entre pintura e cinema, um dos pontos em comum é a composição visual. Ela é constituída por elementos como formas, texturas, linhas, volumes e outros itens que tornam os integrantes visíveis, seja num quadro ou filme. Além desses, estão disponíveis a perspectiva, ponto de fuga e profundidade de campo que, por vezes, podem ser verificados em obras artísticas. Nesse artigo, desejamos verificar até que ponto a organização dos elementos cênicos e escolhas estéticas em Seguindo em frente (2008), de Koreeda Hirokazu, trabalham para auxiliar no avanço narrativo. Para o embasamento teórico, as pesquisas de Jacques Aumont, na área de estudos da imagem e confluência entre artes visuais e cinema, terão destaque e servirão como principal fonte consultada.

Palavras-chave: Cinema japonês. Composição visual. Espacialidade. Narrativa. Enquadramento.

Abstract: In the intersection between painting and cinema one of the points in common between them is visual composition. It is constituted by elements such as shapes, textures, lines, volumes, and other items that become members visible, either in a frame or a film. Besides these perspective, vanishing point and depth of field are available, which can sometimes be verified in pictorial or cinematographic works. In this article we aim to verify the organization of scenic elements and the aesthetics choices in "Still walking" (2008) by Koreeda Hirokazu, actively work in order to assist narrative advance. For theoretical basis the researches of Jacques Aumont in the area of image studies and confluence between visual arts and cinema will highlight and serve as the main source consulted.

Keywords: Japanese cinema. Visual composition. Spatiality. Narrative. Frame.

1 Artigo submetido em 10/11/2018 e aprovado em 13/12/2018.

2 Pós-doutoranda no Programa de Pós-Graduação em Língua, Literatura e Cultura Japonesa (PPGLLCJ) da Faculdade de Filosofia, Letras e Ciências Humanas (FFLCH) da Universidade de São Paulo (USP), São Paulo, Brasil; msugai@gmail.com (ORCID iD: https://orcid.org/0000-0001-5396-4514). 


\section{Introdução}

O espaço cênico encontra-se presente nas artes desde as encenações teatrais promovidas na época da Antiga Grécia, em que os locais não eram construídos visando tal finalidade, mas o desenvolvimento das apresentações.

Nas artes visuais, o espaço é integrante obrigatório, não levando em conta somente a base (tela) onde é produzida, mas igualmente a representação pictórica que nela é criada, e que do mesmo modo é perceptível na fotografia e cinema.

Osvaldo Lópes Chuhurra (apud GENTILE; DÍAZ; FERRARI, 2007) indica uma distinção entre o que ele nomeia espaço cenográfico e espaço plástico (das artes visuais). Enquanto o primeiro é construído baseado no espaço real, o plástico se manifesta em um plano, não é montado, pois se constitui à medida em que é produzido, e tem como característica o fato de não ser visto, mas adivinhado.

Ao assistir uma obra audiovisual, seja uma película no cinema, seriado no canal streaming ou TV a cabo, novela ou vídeo clipe, deparamo-nos com diversos pontos em comum entre eles: atores, estrutura narrativa, temporalidade e espaço onde as ações se desenvolvem.

Levando-se em conta as características que definem o cinema, a espacialidade está presente desde o início, e permanece até os tempos atuais. Jacques Aumont (2004, p. 142) considera o espaço "uma categoria "natural' de nossa percepção", e "enquanto ele é visto, $[\ldots]$ as coisas tornam-se [...] menos simples e menos naturais". Devido ao seu caráter trivial, quando a direção de arte de alguma película se destaca (tal qual nos filmes de Pedro Almodóvar, Jean-Pierre Jeunet, Peter Greenaway e outros), torna-se um chamariz visual, o espaço "abandona" o atributo comum aos olhos e à percepção fílmica, e passa a "distrair" o olhar do espectador.

Ainda sobre o cinema, ao se mencionar ritmo, possivelmente, a primeira ideia que virá à mente é a voltada à edição, a fase da produção cinematográfica em que, dito de modo resumido, após as filmagens, as imagens e sons são ordenados, há acréscimo de dublagem/ narração (caso necessário), sons (música, efeitos sonoros) e outras providências. Contudo, para Mónica Gentile, Rogelio Díaz e Pablo Ferrari (2007, p. 171), ele também está presente na composição visual de um enquadramento, pois, “o ritmo é determinado pela distribuição das massas e pesos visuais em um espaço, criando uma trajetória que conduz o olhar de uma determinada maneira até o elemento principal [...] da composição".

Para complementar, os referidos autores (2007) explanam dois tipos de ritmo utilizados no cinema, o interno e o externo. Entende-se por ritmo interno, os recursos pictóricos como linha, forma, cor, luz, sombra, dimensões, perspectiva e ângulos dos objetos; e os do próprio meio, por exemplo, movimentos de câmera e percurso dos personagens no quadro. Ritmo externo é o promovido pela edição audiovisual.

A partir do mencionado até o momento, procuraremos ampliar e discutir a questão da presença dos elementos cenográficos (explanados a seguir) que formam a 
composição visual de alguns planos do longa-metragem Seguindo em frente (2008), do realizador Koreeda Hirokazu ${ }^{3}$, com o intuito de verificar se os mesmos atuam ativamente na produção de sentido e narrativa da obra cinematográfica em questão.

Devido ao presente texto abordar peculiaridades que tangem as artes visuais e o cinema, em certos momentos do artigo, serão mencionados tópicos em comum a ambas as formas artísticas.

\section{Quadro, perspectiva, ponto de fuga e profundidade}

Os elementos visuais e o espaço visual de qualquer obra artística são delimitados por limites físicos, ou como nomeia Aumont (1993), moldura, que funciona como borda, fronteira material do objeto-imagem. Ela serve como emolduramento, interrompe a imagem e define o domínio ao separá-la do que não faz parte da imagem.

No cinema, o limite/ plano foi debatido por diversos estudiosos, e apresentaremos a seguir, algumas definições. Em O olho interminável: Cinema e pintura, Aumont utiliza o termo quadro cuja definição significa "centraliza a representação, focaliza-a sobre um bloco de espaço-tempo onde se concentra o imaginário" (AUMONT, 2004, p. 40). Em sua outra obra dedicada ao cinema (A estética do filme, 2006), o autor estabelece plano como aquele que abrange dimensões, quadro, ponto de vista, movimento, duração, ritmo, relação com outras imagens/ designa ao mesmo tempo, um certo ponto de vista.

Enquanto que para Gilles Deleuze (1983, p. 18), o enquadramento "compreende tudo o que está presente na imagem, cenários, personagens e acessórios". De acordo com René Gardies (2011), o take inclui imagens captadas entre o princípio e o fim da ação e do registro, constitui um fragmento espaço-temporal homogêneo formado pelo quadro e pelo o que nele aparece e se organiza, além de possuir a especificidade de incluir e excluir. Aída Marques (2007) define plano como a menor unidade audiovisual do ponto de vista técnico. É tudo o que é filmado entre o "ação" e o "corta" do diretor. Apesar de terminologias distintas, o plano (ou outro termo), apresenta a mesma definição citada pelos autores.

Para Edgar Moura, cada diretor de fotografia desenvolve seu próprio estilo de trabalho, resultado do processo do modus operandi para chegar ao plano:

$\mathrm{O}$ estilo resulta do método e do equipamento. Todo mundo tem o seu, mesmo que não o saiba explicar em palavras. Basta lembrar-se da entrevista de Gabriel Figueiroa em que ele dizia não poder definir o seu estilo. [...] (Figueiroa) Começa a pensar alto: Tudo que faço é pensar rápido. Quando me perguntam para aonde eu vou, digo que é preciso definir, primeiro, a perspectiva, depois, a composição, e, por fim, a iluminação. Assim, nessa ordem. Esse é, na realidade, o seu método: primeiro, enquadra, que é o que chama de "perspectiva e composição". Só depois de ver a imagem através do visor da câmera, ilumina. Esse também é seu estilo,

3 Nomes em japonês seguirão o modo padrão da escrita nativa: sobrenome seguido de nome. 
pois quando sublinha a atenção que dá ao grafismo dos seus enquadramentos, lembramos que suas imagens parecem fotos still, onde existem sempre linhas de fuga que atravessam o quadro de um lado a outro e vários planos de interesse no mesmo quadro [...]. (MOURA, 2001, p. 289-290)

Moura reflete sobre o modo como o seu colega de ofício trabalha, cujo método é construído levando-se em conta a ordenação visual, ou seja, quais linhas e formas geométricas estarão em quadro e de que modo. Após essa decisão tomada, ele planeja como o espaço será iluminado, quais integrantes terão destaque, como se dará a sombra e outras decisões a serem tomadas.

Os elementos colocados à vista nos enquadramentos fílmicos são os que nos cercam no mundo real: linhas, volumes, texturas, cores e outros. São eles que delineiam cômodos, mobiliários de cena, paisagens naturais, e demais integrantes. E podem ser colocados para trabalhar em função da narrativa, através de recursos visuais que a direção de fotografia faz uso (como citado por Moura) e explorados na composição visual do quadro.

De acordo com Aumont, enquadrar é o mesmo que emoldurar no cinema, ou seja, tem a ver com composição. $\mathrm{O}$ enquadramento da imagem e o ponto de vista podem designar: "1. Um local, real ou imaginário, a partir do qual uma cena é olhada; 2. O modo particular como uma questão pode ser considerada; 3. [...] uma opinião, um sentimento com respeito a um [...] acontecimento" (AUMONT, 1993, p. 156). Sendo que tais considerações irão, desse modo, influenciar na seleção dos itens participantes da imagem e como serão posicionados.

O mesmo autor compara aspectos fílmicos e pictóricos:

Ambos vêm de uma geometria espectatorial, expressão que cobrirá não apenas os problemas literalmente geométricos de posição respectiva do olho e da imagem [...], como, mais profundamente, [...] os fenômenos perceptivos, às vezes conflitantes, causados pela 'dupla realidade' das imagens. (AUMONT, 2004, p. 62)

Um deles é a profundidade de campo, cujo uso normalmente é creditado por pesquisadores ao longa-metragem Cidadão Kane (Orson Welles, 1941) como o primeiro a ter feito uso do artifício visual. A profundidade permite ao público visualizar o campo espacial existente por trás do objeto focalizado em primeiro plano, até onde o seu olhar for autorizado a tal ato, o que resulta na amplitude do espaço. Aumont (2004, p. 142143) concorda ao apontar que "no real como no quadro, a perspectiva linear [...] permite perceber a profundidade, que ela é até mesmo, em suas diferentes formas, o único fator que permite percebê-la de modo idêntico no real e no quadro".

No cinema, a cenografia não é apenas a técnica perspectivista, e sim a forma aplicável da perspectiva, maneira pela qual as figuras e ações se situam na arquitetura (AUMONT, 2004), ou seja, ela é construída levando-se em consideração não 
exclusivamente o local em si, mas também as necessidades dramáticas, o trânsito de personagens e suas (inter)ações com móveis e objetos cenográficos.

A adoção da perspectiva linear ocidental representou uma revolução no setor pictórico (AUMONT, 2004). Alguns pesquisadores apontam o seu surgimento à época do Renascimento, enquanto outros indicam a sua presença desde o antigo Egito, certamente que não nos mesmos moldes processuais da Renascença, contudo, era possível verificar, por exemplo, a representação superior do faraó em relação aos seus súditos.

Outro modo de utilizar a fórmula anteriormente mencionada pode ser através do uso de linhas, sejam elas arquitetônicas ou resultantes de mobiliários e/ ou objetos cênicos inseridos na espacialidade fílmica, e alcançar o recurso de ponto de fuga, conhecido, segundo Aumont, pelo

[...] papel simbólico inestimável que o centro geométrico da tela-e sua concorrência com o ponto de fuga principal - desempenham na pintura do Quattrocento, onde ele representa nada menos do que o princípio divino [...]. (AUMONT, 2004, p. 113).

Nos filmes produzidos na atualidade, esse recurso pode ser encontrado e utilizado para guiar a mirada do espectador, já que o ponto de fuga resulta na impressão de profundidade e orienta a visão a caminhar até o final do percurso, onde se encontra o ponto central da imagem.

\section{Desenquadramento e centralização}

Dentre outros aspectos imagéticos no cinema, está a centralização que, segundo o teórico David Bordwell (apud AUMONT, 2004), trata-se de uma característica muitas vezes vinculada ao cinema clássico hollywoodiano. Essa escolha foi utilizada para suprir as necessidades narrativas ligadas ao personagem, nas poucas vezes em que se encontrava próximo das bordas do take. Ou seja, quase sempre se tratava de uma operação de centralizar, em que os atores eram mantidos o máximo possível na posição central do quadro, o que forçava o uso de técnicas como o sobreenquadrameneto (procura pela frontalidade e equilíbrio, sempre apresentando relação com o centro da imagem), chegando a frequentes reenquadramentos (pequenos movimentos de câmera destinados a manter o sujeito de volta ao quadro).

Na contramão, há cineastas cujos estilos são fundados na recusa da centralização, priorizando a descentralização ativa e voluntária, ou, de modo mais radical, um desenquadramento. Aumont aborda o tema ao fazer uso das teorias de Rudolf Arnheim quando este menciona de modo simplificado que "as diversas modalidades da descentralização não passam [...] de uma espécie de 'avesso' da centralização" (ARNHEIM apud AUMONT, 2004, p. 129). 
Em seguida, Aumont aponta a possibilidade de diferenciar os termos desenquadramento e descentralização. Ele cita Pascal Bonitzer, que apresenta uma definição distinta da de Arnheim, apontando três características do desenquadramento: "suscita um vazio no centro da imagem; segundo, ele remarca o quadro como borda da imagem; terceiro, $[\ldots]$ ele só pode se resolver na sequencialidade, e, no cinema, tende efetivamente a ela" (ibidem).

Ainda sobre a diferenciação entre ambos, para Aumont, o desenquadramento modifica o equilíbrio entre as funções do plano: "é menos a hipotética e sempre frágil presença dos personagens na borda do quadro do que o caráter ativo, resoluto, marcado dessa borda que conta, ou seja, a ênfase dada ao quadro como limite [...]" (2004, p. 131). Por fim, ele conclui que se pode considerar o desenquadramento o oposto da centralização, já que o olhar do público é levado às bordas do quadro, pois a atenção para o limite do plano é evidenciada e trata-se de uma peculiaridade do cinema (AUMONT, 2004).

Devido ao que foi debatido no parágrafo anterior, consideramos mais apropriado adotar o termo desenquadramento para o desenvolvimento do presente trabalho. Dito isso, daremos continuidade ao andamento ao texto.

A perspectiva é uma característica que antecede o cinema. Ela teve origem oficialmente no século XIV (como anteriormente mencionado). No Japão, seu uso foi praticado a partir da década de 1740, tendo como base os ensinamentos do livro Tratado sobre a arte de pintar (1707), de Gerard de Lairesse (SCHLOMBS, 2010). Até então, na arte plástica tradicional japonesa, os objetos não eram pintados em perspectiva, pois no Japão era utilizada a perspectiva distinta da ocidental, como, por exemplo, perspectiva de cima-para-baixo com telhados ausentes, perspectiva do maior-mais-importante, perspectiva de pontos-de-vista flutuantes e etc. (CORDARO, 2002). O tamanho dos objetos ou figuras humanas não dependia de sua proximidade ou distância do artista, mas da sua importância no contexto da obra.

Por volta de meados do século XIX, teve início o Japonismo ${ }^{4}$, que consistiu no contato de pintores europeus com objetos originários do Japão, iniciados com embrulhos de presentes com estampas de $u k i y o-\hat{e}^{5}$. A partir desse momento, pintores como Vincent Van Gogh, Édouard Manet, Paul Gauguin, Henri de Toulouse-Lautrec, Edgar Degas, entre outros, ficaram impressionados com uma (entre outras) característica específica que passaram a adotar em suas produções: ausência de perspectiva, profundidade e ponto de fuga. Tal atributo nipônico é remetido aos séculos XVIII e XIX, e um dos mais famosos representantes da época é Hokusai Katsushika.

4 Título de um dos artigos que o crítico, colecionador e gravurista francês Philippe Burty publicou, e acabou por nomear o movimento, em 1872.

5 Gênero de pintura (similar à xilogravura) desenvolvida no Japão durante o período Edo (1603-1868). 
Uma vez que a pintura europeia foi "atingida" e influenciada pelo desenquadramento, outro fato estético resultante do Japonismo nas produções de artistas, particularmente em Degas, foi o recorrente "corte" que o pintor promoveu nas figuras pela borda do quadro, conforme visualizado abaixo.

\section{Fig. 1 - Dançarinas azuis (Edgar Degas, por volta de 1898)}

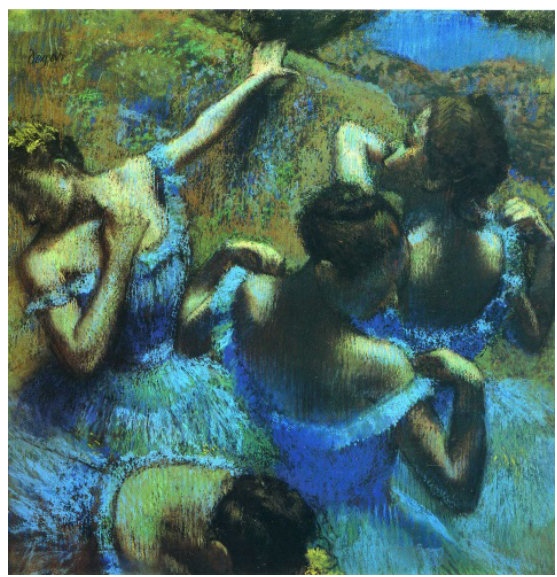

Pastel e papel - 65 x $65 \mathrm{~cm}$

The Pushkin State Museum of Fine Arts (Moscou, Rússia)

Fonte: http://www.arts-museum.ru/data/fonds/europe_and_america/j/2001_3000/6177_

Golubye_tancovschicy/index.php?lang=en

O pintor é conhecido por abordar o universo do balé, dançarinas, performances e bastidores. A obra acima retrata quatro bailarinas em posição próxima uma das outras e seus vestuários na tonalidade azul. A pintura não apresenta profundidade ou ponto de fuga. Não é possível afirmar o local onde se encontram, no entanto, parecem estar se preparando para dançar. Os corpos estão recortados, três delas enquadradas da cintura para cima, e a figura restante abaixo, por estar aparentemente agachada ou no chão, teve parte de sua cabeça e corpo cortados, bem como, em menor parte, a dançarina posicionada à esquerda. Essas são particularidades apontadas por Adele Schlombs na produção do artista: composição assimétrica e cores da névoa que captam o momento (SCHLOMBS, 2010).

Ainda sobre o pintor, Aumont aponta:

[...] especialista dos pontos de vista descentralizados, acrobáticos: descentralização que, às vezes, beira a excentricidade, produção de pontos de vista propositadamente bizarros. Tais enquadramentos são, de fato, reconstituições de instantâneos. Brincando de fazer de conta que eram impressões fotográficas, eles exageram no instante, na decupagem "temporal" e, portanto, na força decisiva do quadro. (AUMONT, 2004, p. 75) 
O autor aponta similaridades entre a criação pictórica de Degas e a proximidade com a fotografia, devido a retratações que mais sugerem o registro improvisado de uma situação que chamou a sua atenção, do que uma produção cuidadosamente elaborada. Devido a essa particularidade estética mais fluída dos pintores que se identificaram com o Japonismo, é mencionado que esse foi um traço que auxiliou no surgimento do movimento impressionista.

As propriedades indicadas por Aumont e Schlombs podem ser reparadas nas obras de Hokusai, como, por exemplo, as apresentadas na imagem 2.

\section{Fig. 2 - Folhas bordôs do outono no rio Tsutaya (Hokusai Katsushika, 1839)}

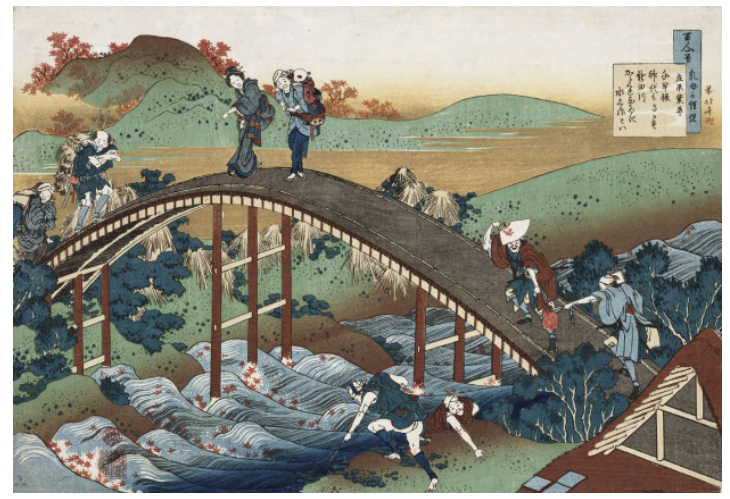

Xilogravura - 25,5 x 37,2 cm. Coleção particular

Fonte: https://www.1000museums.com/art_works/ katsushika-hokusai-autumn-maple-leaves-on-the-tsutaya-river?app_id=88\&from=artists

Além da paisagem natural na obra, percebemos uma ponte e as figuras humanas que a atravessam. Apesar de ela não estar em primeiro plano, a construção é um dos maiores destaques na imagem, devido ao seu posicionamento no centro, considerável massa e promoção de impressão de traspassa-la horizontalmente.

A perspectiva é ausente, a ponte subitamente diminui à altura em que se dirige da metade ao seu final na margem esquerda do rio. Contudo, sua proporção à direita permanece à mesma em toda a extensão até o momento em que é drasticamente rebaixada. $\mathrm{O}$ mesmo pode ser dito sobre a extensão e largura do rio que corre e atravessa a imagem de modo diagonal oposta à ponte. Essa propriedade e a representação das ondas reforçam o seu movimento da direita para a esquerda. Na margem direita do mesmo, há duas figuras masculinas, uma parece pescar, enquanto a outra escala e chega à mesma base do outro personagem. No canto inferior direito do quadro, há o teto de uma casa.

A ausência de perspectiva resulta em um achatamento de todos os elementos (naturais e humanos) presentes na arte. Em decorrência, não há ponto de fuga ou profundidade de campo. A posição do casal no topo da passarela não está ao centro 
da imagem, e sim mais à esquerda, caracterizando desenquadramento. No entanto, a obra como um todo, apresenta uma composição visual equilibrada. $\mathrm{O}$ volume formado acima e à esquerda, ponto mais alto da ponte e quatro figuras nessa extremidade, contrabalançam com os integrantes encontrados no setor inferior à direita, formado pelos quatro personagens e o topo da residência.

Sobre o aspecto do desenquadramento, ele também foi adotado no cinema. Realizadores como Michelangelo Antonioni e Ozu Yasujirō são conhecidos pelo uso dessa estratégia visual. Deleuze (2007) resgatou a hipótese de Bonitzer em relação ao quadro (e/ou plano cinematográfico) para qualificar os planos vazios do cineasta japonês. "Desenquadrar" não significa apenas deslocar objetos e corpos para a lateral do quadro, mas também "enquadrar o vazio". Neste sentido, Ozu seria a vanguarda do cinema moderno, por ter incluído, além de outras formas, o desenquadramento em suas produções.

A questão do desenquadramento em filmes pode ser uma escolha estética, além de justificada pelo fato de, conforme aponta Aumont, indicar uma diferença do campo visual entre pintura e cinema:

[...] O quadro fílmico, por si só, é centrífugo: ele leva o olhar para longe do centro, para além de suas bordas; ele pede, inelutavelmente, o fora-de-campo, a ficcionalização do não visto. Ao contrário, o quadro pictórico é "centrípeto": ele fecha a tela pintada sobre o espaço de sua própria matéria e de sua própria composição: obriga o olhar do espectador a voltar sem parar para o interior, a ver menos uma cena ficcional do que uma pintura, uma tela pintada, pintura [...]. (AUMONT, 2004, p. 111)

Segundo o autor, no cinema, o olhar da audiência não é levado a permanecer no centro da imagem, pois, a partir do momento em que ele está à beira do quadro, a câmera realiza a função de "movimento" no lugar do espectador e transporta-o para outro ângulo que permite melhor visualização da ação (centralizada ou não). Enquanto que, no caso da pintura, por se tratar de uma imagem fixa, o público mantém o olhar no quadro, para que seja levado a imaginar os demais espaços, objetos, personagens, ação e temporalidade retratada.

\section{Análise da obra fílmica Seguindo em frente}

Seguindo em frente é o décimo primeiro filme dirigido por Koreeda, de uma lista de 24 produções até o momento, número contabilizado entre obras documentais e ficcionais, exibidos em salas de cinema ou TV.

$\mathrm{O}$ enredo trata do encontro num quente fim de semana, das três gerações da família Yokoyama na residência dos patriarcas, para homenagear o filho morto (fato ocorrido quando tenta socorrer um garoto que estava a se afogar). 
Para compor as imagens, planos estáticos de longa duração são usados com frequência. A maior parte das sequências da película se passa nos cômodos do interior da casa familiar, em especial a cozinha e sala de jantar. Iniciaremos, portanto, a análise a partir deles.

\section{Fig. 3 - Parte da família reunida na cozinha}

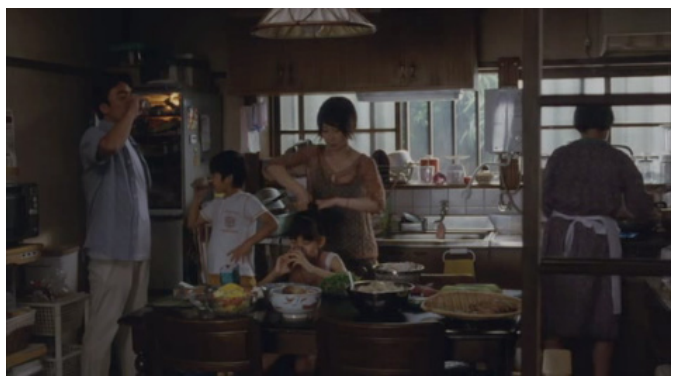

Fig. 4 - Família Yokoyama almoçando na sala de jantar

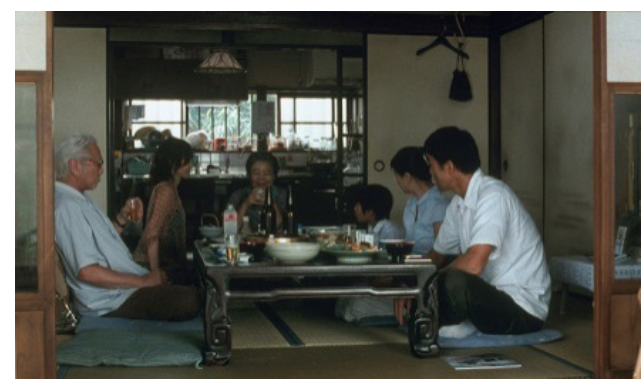

Fonte: Fotogramas de Seguindo em frente

Apesar de as imagens acima conterem linhas verticais e horizontais, retas, volumes, formas, texturas, curvas, cores e demais elementos visuais humanos e cênicos, percebemos que se trata de planos que se passam na cozinha; especificamente a figura 3, apresentada no início do filme, quando a avó e filha preparam alimentos juntas, até que o genro e netos da matriarca chegam de um passeio e se refrescam. A outra imagem engloba a anterior, pois o posicionamento e enquadramento de câmera estão mais abertos, o que permite a captação da sala de jantar em primeiro plano, e a cozinha ao fundo.

Além de os elementos visuais que compõem o take, acrescido dos que os formam, profundidade e ponto de fuga, bem como o posicionamento dos atores, percebe-se que a integrante em destaque de ambas as situações é a avó.

$\mathrm{Na}$ imagem à esquerda, visualizamos as linhas horizontais e verticais da bancada, pia e janela da cozinha (destacadas devido à iluminação), outras retas menores são percebidas pelas que compõem geladeira, base das mesas e elemento vazado sobre a avó. Ao acompanharmos a linha lateral da base da mesa (localizada na parte inferior do cenário e ao centro), e as mesmas partes que estão à sua esquerda, nota-se que as retas transversais levam ao ponto de fuga que culmina na idosa. Ela destaca-se ainda mais, pois está isolada à direita do frame, cercada por um espaço "livre" como uma redoma à sua volta que a separa do grupo posicionado do lado oposto.

$\mathrm{Na}$ outra imagem (figura 4), as mesmas linhas horizontais e verticais da cena anterior na cozinha estão presentes mais ao fundo do plano. O fato de todos os elementos visuais estarem em foco resulta no efeito de profundidade de câmera. Portanto, o olhar 
do público percebe que por trás da sala de jantar (em primeiro plano), há outro recinto que segue no fundo do campo visual enquadrado e expandido.

Gentile, Díaz e Ferrari comentam sobre a produção desse efeito:

[...] Outra forma de tridimensionalizar cenograficamente o plano visual é por meio da inserção de diagonais no espaço. Uma linha diagonal desde a borda do enquadramento até o centro constitui uma tridimensão efetiva que será materializada por uma viga no teto de um estábulo ou de uma igreja destruída, uma paliçada ${ }^{6}$ ao infinito [...]. (2007, p. 182)

Nessa tomada, há outras retas presentes, formadas pelas portas divisórias dos cômodos, pés e base da mesa em primeiro plano. As linhas transversais são as do tampo da mesa, tatame, e fusuma à direita. Elas têm como ponto de fuga a cozinha, orientam o olhar do espectador ao centro da imagem, onde a personagem que ocupa a cabeceira da mesa é a responsável por conduzir o espaço da cozinha, localizado posteriormente à ela. Aqui, ela também aparece "isolada", seus familiares formam duas paredes ao seu redor, sendo que as suas alturas constituem duas diagonais que reforçam o olhar para a atriz. Trata-se de uma tomada interessante, onde os personagens, com exceção da matriarca, estão um de frente para o outro, e a senhora é a única cuja posição está frontalmente dirigida à câmera. Apesar de ela estar mais afastada do público, é a que tem a visualização mais privilegiada. Contudo, indica um caso de desenquadramento, ela não está posicionada no meio da imagem; apesar de a sua posição ser o centro de atenção visual pelas particularidades apresentadas, só toma esse posto quando o conjunto da imagem é analisado.

As formas circulares também estão presentes em Seguindo em frente, como se pode notar nas imagens abaixo, que pertencem a passagens em ambiente exterior.

6 Cerca feita com estacas apontadas e fincadas na terra.

7 Porta de correr de lares japoneses que pode ser movida, permitindo ampliar ou reduzir a dimensão do espaço, conforme a necessidade. 


\section{Fig. 5 - Avô durante passeio}

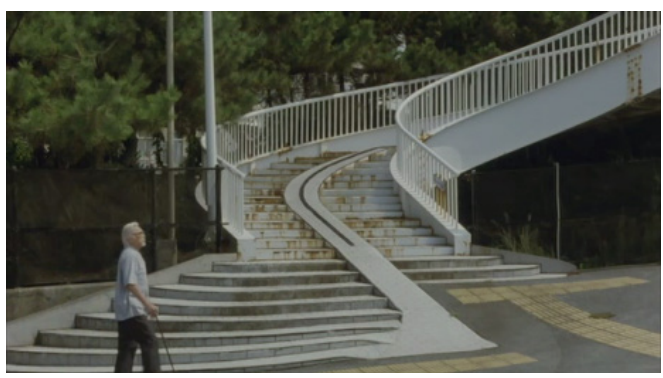

\section{Fig. 6 - Avô, filho e neto} atravessando passarela

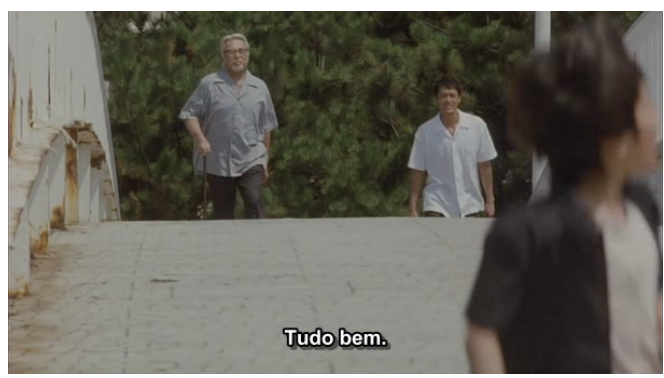

Fonte: Fotogramas de Seguindo em frente

A figura 5 é uma das cenas iniciais do longa-metragem, quando o avô sai para passear pelo bairro e passa em frente à plataforma, não a atravessando. As formas arquitetônicas da escada e corrimão dominam o plano. O formato dos primeiros degraus parece se expandir em direção à parte inferior do quadro, retomam força visual quando a base da estrutura deixa de ser o chão e começam a traçar curvatura para a direita do quadro.

A figura humana aparece diminuta frente à construção, a sua presença encaixa-se no termo que Moura nomeia como segundo centro de interesse, utilizado na fotografia, mas que pode ser aplicado na cena:

O segundo centro de interesse de uma foto é algo além da primeira leitura. Existem vários possíveis. Cartier-Bresson usa a composição e um grafismo rigoroso que são típicos da pintura. Ele era pintor antes de ser fotógrafo. Nas suas fotos, depois de entendermos do que tratam, ainda sentimos um fascínio pela composição da imagem. É por causa da disposição dos elementos pelo quadro que continuamos a olhar uma foto de Cartier-Bresson. Nela, as pessoas nunca estão encavaladas ou se cobrindo. Cada personagem de uma foto de Cartier-Bresson tem seu lugar certo dentro do quadro. (MOURA, 2001, p. 390)

Apesar de a atenção ser voltada à forma arquitetônica, o ator é reparado em algum momento, por estar em primeiro plano e mover-se no quadro.

A imagem 6 faz parte de uma dos momentos quase ao final do filme. Após o primeiro dia turbulento da reunião familiar, devido às intrigas, no segundo dia de convivência, os ânimos parecem ter se acalmado. As três figuras masculinas decidem ir à praia, e para alcançar o seu destino, necessitam percorrer a construção elevada.

A linha horizontal parecer servir como uma divisória, o neto está à frente, correndo. Ele ainda é jovem, avança sem receios. No espaço anterior à linha, surge 
o filho seguido do avô. Os adultos são mais cautelosos e não possuem a vitalidade juvenil. As linhas verticais do corrimão formam uma massa, impedindo distinguir a sua individualidade nas unidades que se encontram na profundidade de campo. Aqui, as linhas curvas também se destacam, são as da base da passarela e corrimão, elas seguem em "queda" ao fundo do plano.

A passarela também está presente em Maboroshi - A luz da ilusão (1995), de Koreeda.

Fig. 7 - Avó e neta na passarela

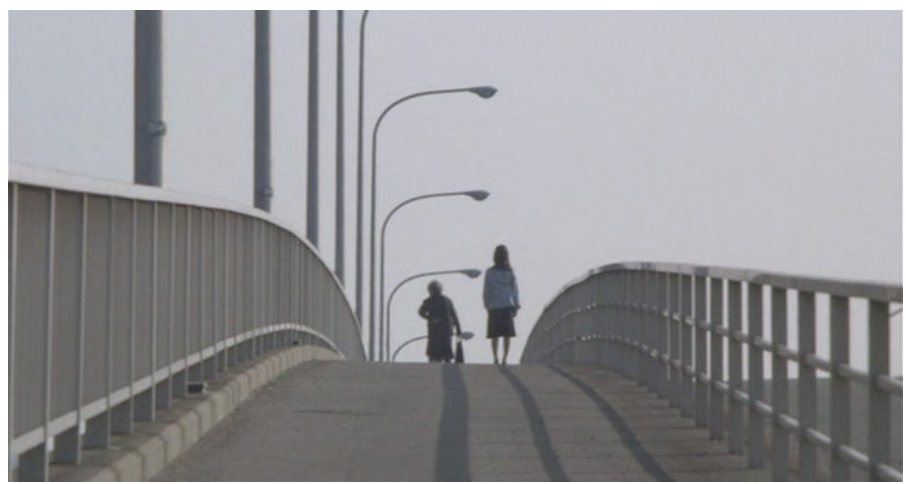

Fonte: Fotograma de Maboroshi

No início do filme, a avó da protagonista deixa a casa onde residiam, pois ela deseja retornar à sua cidade-natal para falecer. A cena da imagem acima exibe o momento em que a jovem segue a idosa até a construção, porém, como a senhora se mostra irredutível em retornar, a adolescente não vê outra saída senão deixa-la ir. As figuras das atrizes parecem se misturar com as linhas verticais do corrimão da ponte e dos postes de iluminação. As retas que se dirigem ao fundo da imagem são compostas pelas do corrimão e sombras projetadas no chão da plataforma, que orientam visualmente o olhar do público em direção ao volume formado pelas personagens, de modo que sempre acabam por se dirigir a elas. Outro ponto que evita distração é o fato de o topo da plataforma estar quase no centro do quadro.

As linhas curvas são menos acentuadas do que em Seguindo em frente, contudo, a posição da câmera é semelhante, não enquadra a construção arquitetônica integralmente, somente até certo ponto. Além dessa equivalência, os fotogramas de ambos os filmes mostram momentos de ruptura entre os familiares. Na obra mais antiga, a separação da avó marca a vida de sua neta durante toda a narrativa fílmica. Em Seguindo em frente, na figura 5, é como se o avô não conseguisse fazer a travessia sozinho. Na seguinte, o individualismo e egoísmo do patriarca e de seu filho parecem ter sido deixados de lado, como se trabalhassem em prol de algo maior, uma conciliação para o bem estar familiar. Desta vez, os personagens atravessam 
a passarela juntos, significando o rompimento de algo que permaneceu no passado. Na praia, fazem promessas de novos encontros (que não chegam a cumprir) e apontam, nesse instante do enredo, harmonia entre passado, presente e futuro.

\section{Conclusão}

Diversos elementos visuais fizeram parte das artes antes mesmo de serem produzidas para tal propósito. Linhas, volumes, cores e outros estão entre os invariavelmente presentes na pintura, fotografia e cinema, guiando o olhar do público.

O cinema é uma arte visual originária das que surgiram anteriormente a ele, portanto, torna-se natural que, apesar de aspectos distintos de linguagem, haja outros que se interceptem.

A espacialidade é formada pelos itens anteriormente mencionados, que compõem os ambientes presentes nas criações pictóricas e fílmicas. Seja em uma ou em outra, toda imagem é delimitada pela moldura e enquadramento.

Os elementos que formam os itens visíveis nas obras artísticas são até hoje utilizados para produzir efeitos desejados pelo criador. No cinema, devido à utilização de variados tipos de takes, o realizador possui esse ponto ao seu favor para auxiliá-lo a contar o enredo de forma mais clara, ou até mesmo manipular a audiência (tática usada por Alfred Hitchcock).

Os cenários do longa-metragem Seguindo em frente são formados por elementos factíveis de serem encontrados no mundo natural, e não levados ao extremo, como na estética utilizada pelo Impressionismo alemão com seus cenários distorcidos e fotografia contrastada.

Os ambientes registrados na película de Koreeda são capturados, em sua grande maioria, por planos estáticos que permitem a visualização total ou parcial dos recintos. Alguns deles têm profundidade, resultado da perspectiva dos espaços e/ ou móveis e adereços cenográficos que compõem os locais de filmagem. O trio pertencente à equipe criativa faz uso dos mesmos para organizar o quadro, e através das linhas dos móveis, paredes, tatame e demais, promovem a sensação de espaços mais amplos, adquiridos através da distância (real ou não) entre os elementos posicionados em primeiro e segundo plano, respectivamente, ponto mais próximo e distante da câmera/ audiência.

Koreeda faz uso de outro recurso visual disponível: o ponto de fuga. Ele é requisitado quando há a necessidade de dirigir o olhar do público, que, por vezes, necessita de orientação espacial para alcançar e identificar o objeto central do plano. E também, em virtude de, alguns planos de o filme corpus desse texto terem duração mais longa, o espectador pode, por vezes, se "perder", e o mecanismo auxilia no retorno ao ponto de atenção, ou mesmo para indicar o personagem em destaque em determinada cena.

Por vezes, a espacialidade fílmica pode passar despercebida, contudo, ela e seus constituintes são elementos ativos no enredo, ou seja, o ritmo, pelo menos em Seguindo em frente, funciona para auxiliar em inúmeros aspectos e situações narrativas.

O desenquadramento na película talvez possa ser considerado uma opção estética mais habitual para Koreeda, visto que é uma escolha de quadro da qual outros realizadores fizeram uso, entre eles Ozu, a quem o seu trabalho é frequentemente comparado, sem se esquecer da possibilidade do legado estético de (des)enquadramento de Hokusai. 


\section{Referências Bibliográficas}

AUMONT, J. O olho interminável: Cinema e pintura. Trad. Eloisa Araújo Ribeiro. São Paulo, Cosac e Naify, 2004. 1993.

. A imagem. Trad.: Esteia dos Santos Abreu e Cláudio C. Santoro. Campinas, SP: Papirus,

AUMONT, J. et al. A estética do filme. Trad. Marina Appenzeller. Campinas: Papirus Editora, 2006.

AUMONT, J; MARIE, M. Dicionário teórico e crítico de cinema. Trad. Eloisa Araújo Ribeiro. Campinas: Papirus, 2003.

CHEVALIER, J.; GHEERBRANT, A. Dicionário de los símbolos. Trad. Manuel Silvar e Arturo Rodríguez. Barcelona: Editorial Herder, 1986.

CORDARO, Madalena N. H. Pintura e escritura do mundo flutuante: Hishikawa Moronobu e ukiyo-e Ihara Saikaku e ukiyo-zôshi. São Paulo: Hedra, 2002.

DELEUZE, G. Cinema 1 - A imagem - movimento. Trad. Stella Senra. São Paulo: Editora Brasiliense S.A., 1983 2007.

A imagem-tempo: cinema 2. Trad. Eloisa de Araujo Ribeiro. São Paulo: Brasiliense,

GARDIES, R. (org.). Compreender o cinema e as imagens. Lisboa: Edições Texto \& Grafia, 2011.

GENTILE, M.; DÍAZ, R.; FERRARI, P. Escenografia cinematográfica. Buenos Aires: La Crujía, 2007.

HAMBURGER, V. Arte em cena - A direção de arte no cinema brasileiro. São Paulo: Sesc, 2014.

KATO, S. Tempo e espaço na cultura japonesa. Trad. Neide Nagae e Fernando Chamas. São Paulo: Estação Liberdade, 2012.

MARQUES, A. Ideias em movimento: produzindo e realizando filmes no Brasil. Rio de Janeiro: Rocco, 2007.

MORSE, E. S. Lares japoneses: seus jardins e arredores. Trad. Mário Salviano. Rio de Janeiro: Editorial Nórdica Ltda., 1886.

MOURA, E. 50 anos luz, câmera e ação. São Paulo: Editora SENAC, 2001.

NOVIELli, M. R. História do cinema japonês. Trad. Lavínia Porciúncula. Brasília: Universidade de Brasília, 2007.

RATTO, G. Antitratado de cenografia: variações sobre o mesmo tema. São Paulo: Editora SENAC, 1999.

SCHLOMBS, A. Hiroshige. Lisboa: Taschen, 2010. 